\title{
Genetic dissection for head blast resistance in wheat using two mapping populations
}

\author{
Xinyao $\mathrm{He}^{1}$, Muhammad Rezaul Kabir ${ }^{2}$, Krishna K. Roy ${ }^{2}$, Felix Marza ${ }^{3}$, Aakash Chawade ${ }^{4}$, Etienne Duveiller ${ }^{1}$, \\ Carolina Saint Pierre (iD ${ }^{1}$ and Pawan K. Singh (iD) ${ }^{1 凶}$ \\ (c) The Author(s) 2021
}

\begin{abstract}
Wheat head blast is a dangerous fungal disease in South America and has recently spread to Bangladesh and Zambia, threatening wheat production in those regions. Host resistance as an economical and environment-friendly management strategy has been heavily relied on, and understanding the resistance loci in the wheat genome is very helpful to resistance breeding. In the current study, two recombinant inbred line (RIL) populations, Alondra/Milan (with 296 RILs) and Caninde\#2/Milan-S (with 254 RILs and Milan-S being a susceptible variant of Milan), were used for mapping QTL associated with head blast resistance in field experiments. Phenotyping was conducted in Quirusillas and Okinawa, Bolivia, and in Jashore, Bangladesh, during the 2017-18 and 2018-19 cropping cycles. The DArTseq technology was employed to genotype the lines, along with four STS markers in the 2NS region. A QTL with consistent major effects was mapped on the 2NS/2AS translocation region in both populations, explaining phenotypic variation from 16.7 to $79.4 \%$ across experiments. Additional QTL were detected on chromosomes $2 \mathrm{DL}, 7 \mathrm{AL}$, and 7DS in the Alondra/ Milan population, and 2BS, 4AL, 5AS, 5DL, 7AS, and 7AL in the Caninde\#2/Milan-S population, all showing phenotypic effects $<10 \%$. The results corroborated the important role of the 2NS/2AS translocation on WB resistance and identified a few novel QTL for possible deployment in wheat breeding. The low phenotypic effects of the non-2NS QTL warrantee further investigation for novel QTL with higher and more stable effects against WB, to alleviate the heavy reliance on 2NS-based resistance.
\end{abstract}

Heredity (2022) 128:402-410; https://doi.org/10.1038/s41437-021-00480-3

\section{INTRODUCTION}

Wheat blast (WB) is an emerging fungal disease with great potentiality in causing large-scale yield reduction in the tropical and subtropical wheat production areas. The disease is caused by the ascomycete fungus Magnaporthe oryzae pathotype Triticum (MoT) under warm and humid conditions (Cruz and Valent 2017; Kohli et al. 2011). Traditional epidemic regions include South American countries Brazil, Bolivia, Paraguay, and Argentina, and in the last few years, WB incidence has been reported in Bangladesh (Malaker et al. 2016) and Zambia (Tembo et al. 2020), posing a great threat to their neighboring countries in Asia and Africa, respectively, considering the fact that MoT is both seed- and air-borne. Based on climate analogy, WB vulnerable areas of 7 million ha were identified in India, Pakistan and Bangladesh, from where an annual yield reduction of 0.89-1.77 million tons of wheat may occur under WB conducive conditions (Mottaleb et al. 2018). Additional WB-prone areas have been identified in the USA, Ethiopia and Australia, especially under the scenario of global warming (Cao et al. 2011; Cruz et al. 2016a; Duveiller et al. 2011; Maciel 2011).

Although MoT can infect all the aerial parts of wheat, head blast on spikes is the most conspicuous symptom, often causing severe yield losses under favorable conditions on susceptible wheat varieties (Kohli et al. 2011). Disease development of WB is very fast, and the entire spikes may become bleached only a few days after the first symptom is seen, leaving no time for remedial actions like fungicide application (Duveiller et al. 2016). In South America, farmers often apply fungicides two to three times around the anthesis period to prevent this disease, yet severe yield loss may occur, as demonstrated in Brazil during the 2005 WB epidemic, when $14-32 \%$ yield reduction was recorded for two widely grown varieties despite two applications of fungicide (Urashima et al. 2009). In addition to the low effectiveness, the fast development of resistant fungal isolates is another factor to compromise fungicidal application, due to the high evolving rate of MoT (Castroagudín et al. 2015). This is also a major difficulty for resistance breeding, and there have been many varieties initially identified as WB resistant that became susceptible in later experiments or in largescale cultivation (Cruz and Valent 2017). Nevertheless, varietal resistance has been heavily relied on both in South America and South Asia, due to its low cost and ease of adoption, which is especially important for small-scale, resource-poor farmers having limited access to other WB management tools.

Great efforts have been made on germplasm screening for WB resistance, yet no immunity has been identified, and the source of resistance has been limited, mostly being 2NS/2AS translocation carriers (Cruppe et al. 2020a; He et al. 2021; Juliana et al. 2020). This translocation was introduced from Aegilops ventricosa to utilize the rust resistance genes Lr37, Sr38, and Yr17 (Helguera

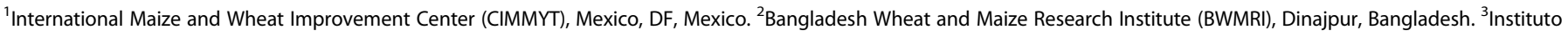

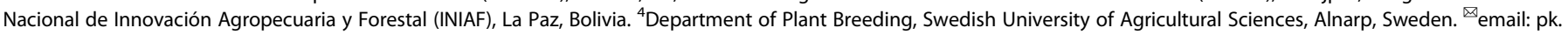
singh@cgiar.org 

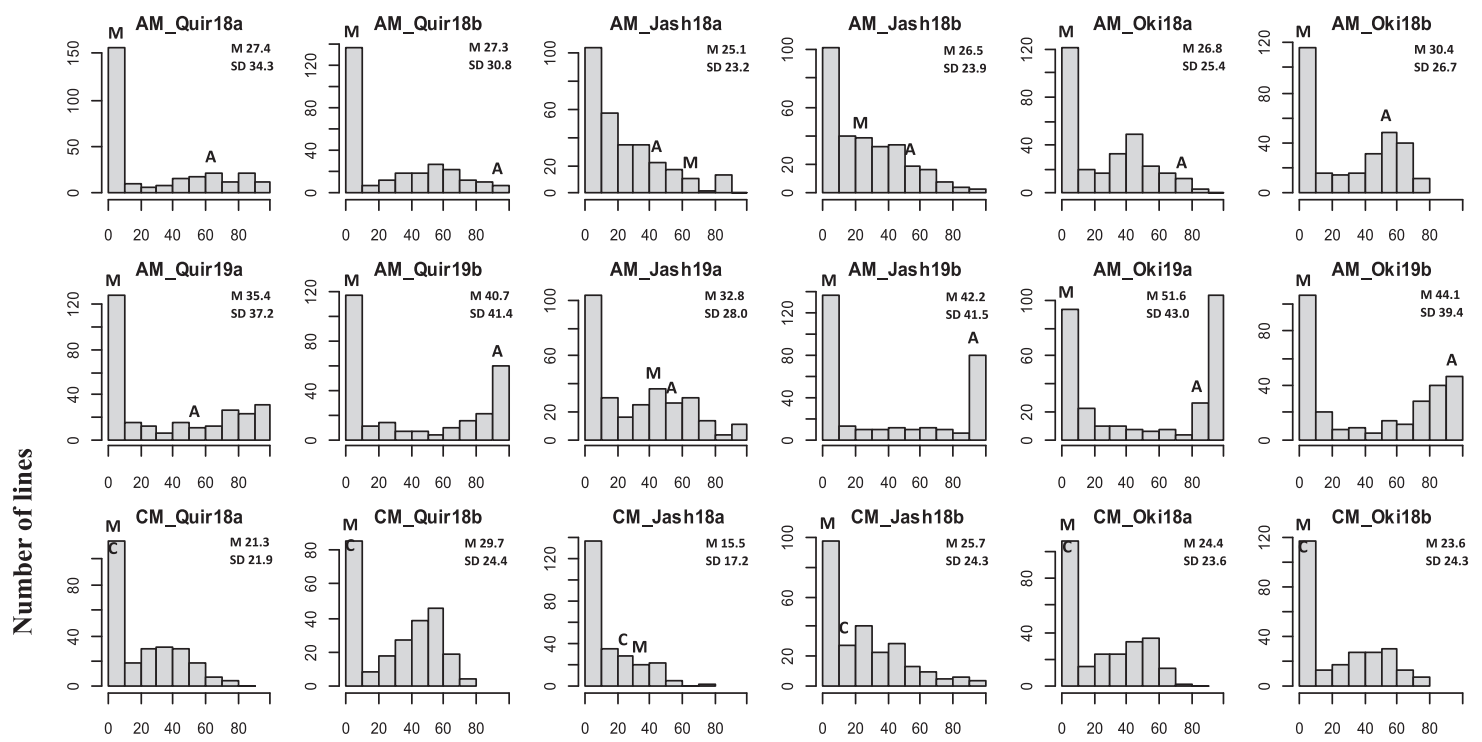

AM Jash19a
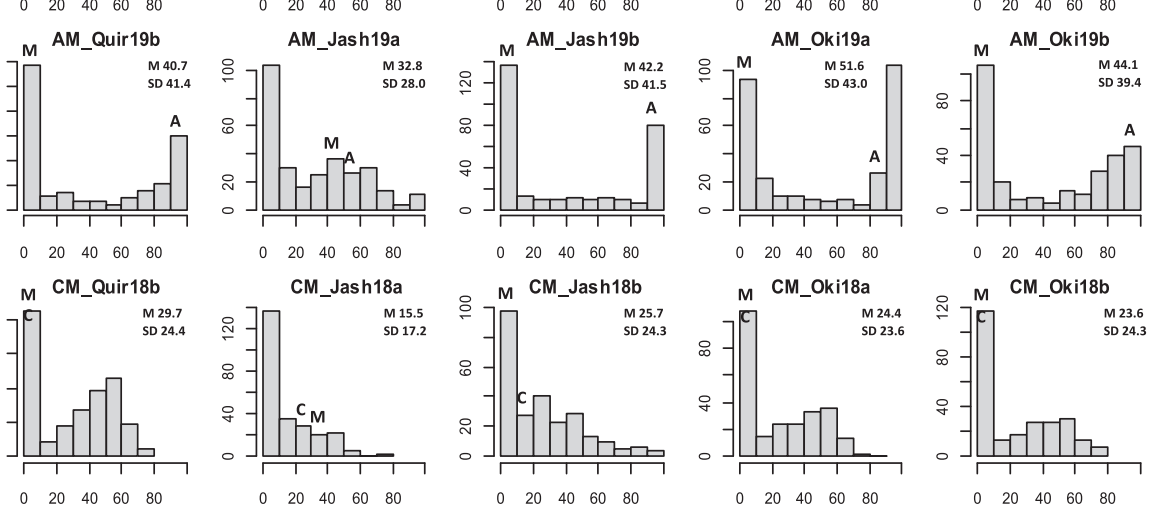

$\begin{array}{llllll}0 & 20 & 40 & 60 & 80\end{array}$
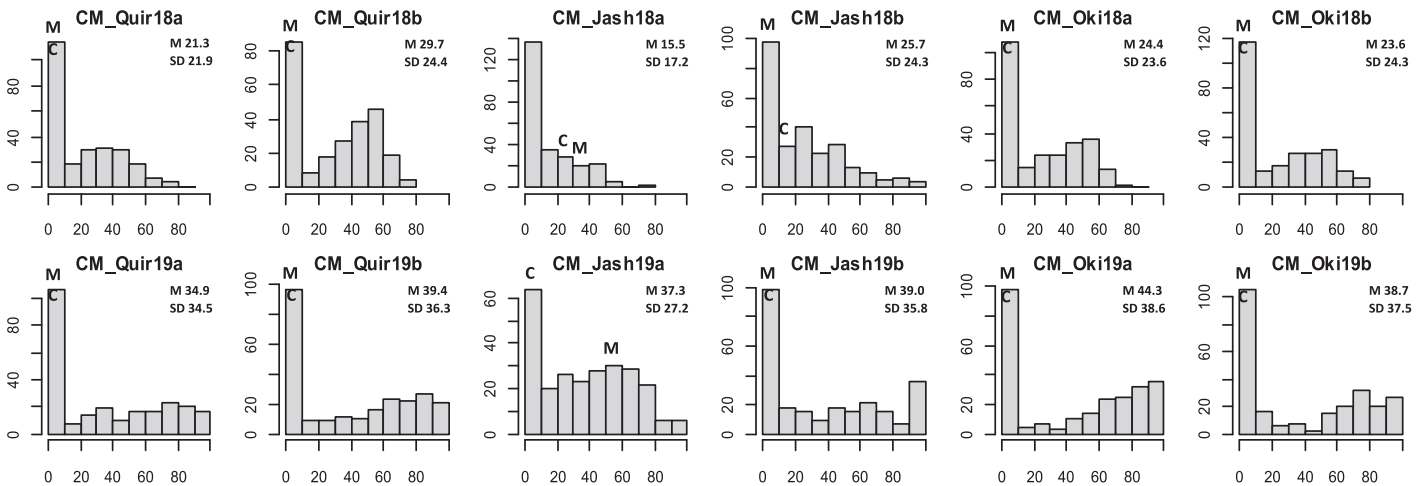

Wheat blast index (\%)

Fig. 1 Histograms of wheat blast index for the populations Alondra/Milan (AM) and Caninde\#2/Milan-S (CM) in individual experiments. Phenotypic ranges of the two parents are indicated, where A stands for Alondra, C for Caninde\#2 and M for Milan-S. "Quir" stands for Quirusillas, "Jash" for Jashore, and "Oki" for Okinawa, "18" and "19" for the 2017-18 or 2018 cycle and 2018-19 or 2019 cycle, respectively, and "a" and "b" for the first and second sowing, respectively. Grand mean (M) and standard deviation (SD) values are presented for all experiments.

et al. 2003) and was later found to confer good WB resistance (Cruz et al. 2016b). Although its effect on WB resistance has been eroded by new MoT isolates (Cruppe et al. 2020a), 2NS-based resistance remains to be the corner-stone of the control strategy in most WB epidemic regions, where the large-scale sown varieties are mostly 2NS carriers, such as Sossego and CD 116 in Brazil, Caninde\# 1 in Paraguay, and Urubo and INIAF Tropical in Bolivia (Cruppe et al. 2020a; He et al. 2021). Due to the significant effects on yield advantage and rust resistance, the frequency of genotypes harboring 2NS has increased to around 90\% in CIMMYT materials released after 2015 (Juliana et al. 2020; Juliana et al. 2019).

Genetics for host resistance against WB has mostly been investigated at the seedling stage, and a few resistance genes have been identified, including $R m g 2, R m g 3, R m g 7, R m g 8$, and $R m g G R 119$, of which the latter three also conferred resistance against head blast infection (He et al. 2020a; Singh et al. 2021). According to Cruz and Valent (2017), however, Rmg7 has been defeated by recent MoT isolates, whereas Rmg8 and RmgGR119 still need to be tested against the new MoT isolates in field experiments. Recent genetic studies on head blast resistance have confirmed the major effects of 2NS/2AS translocation, along with a few QTL or marker-trait associations (MTA) with minor effects that were less stably expressed across environments or experiments (Cruppe et al. 2020b; Ferreira et al. 2020; Goddard et al. 2020; He et al. 2021; Juliana et al. 2020; Wu et al. 2021).

In our previous study on the Caninde\#1/Alondra population, a major QTL for head blast resistance was identified on the 2NS/2AS translocation region, explaining phenotypic effects between 22.4 and $50.1 \%$ across 12 field experiments, and minor QTL were identified on chromosomes $1 \mathrm{AS}, 2 \mathrm{BL}, 3 \mathrm{AL}, 4 \mathrm{BS}, 4 \mathrm{DL}$, and $7 \mathrm{BS}$
(He et al. 2020b). The aims of the present study were to map two more populations, Alondra/Milan and Caninde\#2/Milan-S, for head blast resistance and to identify molecular markers suitable for marker-assisted selection (MAS).

\section{MATERIALS AND METHODS \\ Plant material}

Two recombinant inbred line (RIL) populations, Alondra/Milan (referred to as AM hereafter) with 296 RILs and Caninde\#2/Milan-S (CM) with 254 RILs, were developed via the single seed descend method to $F_{2 \cdot 7}$ generation. The parent Alondra has a pedigree of D-6301/NAINARI-60//WEIQUE/RED$\mathrm{MACE} / 3 / \mathrm{CIANO}-\mathrm{F}-67^{*} 2 / \mathrm{CHRIS}$, which is a $2 \mathrm{AS}$ carrier and is susceptible to WB. Caninde\#2 is a 2 NS variety released in Paraguay due to its good WB resistance (Duveiller et al. 2016), with a pedigree of ITAPUA-35-APEREA/PF84432//CORDILLERA-4. The parent Milan is a well-known CIMMYT wheat line that has a pedigree of VS-73-600/MAIORAL/3/BOBWHITE/YECORA-70// TRIFON. It has frequently been used as a WB resistance donor and many of its derivatives also have good WB resistance due to the presence of the 2NS/2AS translocation (Kohli et al. 2011). However, in our recent study, residual heterozygosity was found in the $2 \mathrm{NS} / 2 \mathrm{AS}$ translocation region of Milan, and the presence of WB susceptible Milan lines (denoted as Milan-S) that have the 2AS segment were also reported (He et al. 2021). The Caninde\#2/Milan-S population was initially made for breeding purposes, but it demonstrated strong segregation of WB resistance among the RILs, implying that Milan-S, instead of a 2NS Milan line (Milan-R), was used to generate the population. Therefore, the Caninde\#2/Milan-S population was also included in this study to map WB resistance.

\section{Inoculum preparation}

The inoculum used in this study was composed of locally collected MoT isolates that had shown a high capacity of sporulation, including OKI1503, OKI1704, QUI1505, QUI1601, and QUI1612 in Bolivia and BHO17001, 
Table 1. Analysis of variance for wheat blast index and its heritability estimates in different locations for the populations Alondra/Milan (AM) and Caninde\#2/Milan-S (CM).

\begin{tabular}{|c|c|c|c|c|c|c|c|}
\hline Pop. & Location & Source & DF & Mean square & $F$ value & $P$ value & Heritability \\
\hline \multirow[t]{12}{*}{ AM } & Quirusillas & Genotype & 293 & 3354.35 & 10.76 & $<0.0001$ & 0.71 \\
\hline & & Year & 1 & 40187.86 & 128.96 & $<0.0001$ & \\
\hline & & Sowing (year) & 1 & 2423.97 & 7.78 & 0.0057 & \\
\hline & & Genotype $\times$ year & 275 & 998.90 & 3.21 & $<0.0001$ & \\
\hline & & Genotype $\times$ sowing & 287 & 305.51 & 0.98 & 0.5652 & \\
\hline & & Error & 246 & 311.62 & & & \\
\hline & & Sowing (year) & 1 & 4444.87 & 10.61 & 0.0013 & \\
\hline & & Genotype $\times$ year & 295 & 587.40 & 1.40 & 0.0019 & \\
\hline & & Genotype $\times$ sowing & 295 & 437.37 & 1.04 & 0.3567 & \\
\hline & & Error & 293 & 419.01 & & & \\
\hline & & Genotype $\times$ sowing & 295 & 162.81 & 1.02 & 0.4273 & \\
\hline & & Error & 287 & 159.33 & & & \\
\hline \multirow[t]{12}{*}{$\mathrm{CM}$} & Quirusillas & Genotype & 253 & 2510.31 & 12.60 & $<0.0001$ & 0.75 \\
\hline & & Year & 1 & 32988.66 & 165.58 & $<0.0001$ & \\
\hline & & Sowing (year) & 1 & 1009.74 & 5.07 & 0.0253 & \\
\hline & & Genotype $\times$ year & 252 & 614.32 & 3.08 & $<0.0001$ & \\
\hline & & Genotype $\times$ sowing & 250 & 212.20 & 1.07 & 0.3112 & \\
\hline & & Error & 241 & 199.23 & & & \\
\hline & Jashore & Genotype & 253 & 1714.67 & 4.64 & $<0.0001$ & 0.73 \\
\hline & & Year & 1 & 78005.70 & 210.99 & $<0.0001$ & \\
\hline & & Sowing (year) & 1 & 1353.29 & 5.96 & 0.0153 & \\
\hline & & Genotype $\times$ year & 253 & 443.17 & 1.95 & $<0.0001$ & \\
\hline & & Genotype $\times$ sowing & 253 & 219.16 & 0.97 & 0.6084 & \\
\hline & & Error & 252 & 226.89 & & & \\
\hline
\end{tabular}

MEH17003, GOP17001.2, RAJ17001, CHU16001.3, and JES16001 in Bangladesh. The isolates were grown on oatmeal agar plates for sporulation, and the harvested conidia were adjusted to a concentration of 80,000 spores/ $\mathrm{ml}$ using a hemocytometer under a microscope, and finally, Tween-20 was added to make a concentration of $0.02 \%$ before field application. For more technical details, refer to He et al. (2020b).

\section{Field experiments}

The field experiments were conducted in three locations over 2 years, involving the 2017-18 and 2018-19 cycles in Quirusillas (Bolivia) and Jashore (Bangladesh), and the 2018 and 2019 cycles in Okinawa (Bolivia). Two sowings that were separated by around 2 weeks were made in each location to expose the populations to wider environmental conditions, and no replication was made within each sowing. The experiments in this study were denoted according to location ("Quir" for Quirusillas, "Jash" for Jashore, and "Oki" for Okinawa), cropping cycle ("18" for the 2017-18 or 2018 cycle, and "19" for the 2018-19 or 2019 cycle), and sowing ("a" and "b" for the first and second sowings, respectively). Both Quirusillas and
Okinawa are located in the Department of Santa Cruz of Bolivia, but the former is in the high land region with a cropping season from December to April, and the latter is in the lowland region with a cropping season from May to August. Jashore is located in the Division of Khulna, Bangladesh, and has a cropping cycle from December to April.

The two mapping populations were sown in $1 \mathrm{~m}$ double rows spaced $20 \mathrm{~cm}$ apart. To create a WB conducive micro-environment, a misting system was used in the field that worked $10 \mathrm{~min}$ each hour from 8 a.m. to 7 p.m. The resistant checks used were Urubo in Bolivia and BARI Gom 33 in Bangladesh, and the corresponding susceptible checks were Atlax and BARI Gom 26, respectively. At the anthesis stage, ten spikes were tagged with sticky paper tape for later WB evaluation, which were selected from different plants of a RIL to increase representativity, and the spikes were spray inoculated with a $\mathrm{CO}_{2}$ driven backpack sprayer in the evening. Inoculation was repeated 2 days later to ensure that late spikes were inoculated. According to the disease progress, field evaluation was conducted at 14 or 21 days after the first inoculation, and the ten inoculated and marked spikes were counted for numbers of total spikelets and that of infected spikelets. WB index was calculated via multiplying 
Table 2. Pearson correlation coefficients of wheat blast index across experiments for the populations Alondra/Milan (below the diagonal) and Caninde\#2/Milan-S (above the diagonal).

\begin{tabular}{l|r|r|r|r|r|r|r|r|r|r|r|r|r|}
\hline & Quir18a & Quir18b & Jash18a & Jash18b & Oki18a & Oki18b & Quir19a & Quir19b & Jash19a & Jash19b & Oki19a & Oki19b \\
\hline Quir18a & 1 & 0.69 & 0.41 & 0.32 & 0.51 & 0.58 & 0.56 & 0.59 & 0.46 & 0.53 & 0.65 & 0.60 \\
\hline Quir18b & 0.74 & 1 & 0.52 & 0.38 & 0.58 & 0.57 & 0.59 & 0.62 & 0.51 & 0.55 & 0.69 & 0.61 \\
\hline Jash18a & 0.30 & 0.38 & 1 & 0.38 & 0.51 & 0.52 & 0.49 & 0.55 & 0.45 & 0.61 & 0.58 & 0.46 \\
\hline Jash18b & 0.31 & 0.41 & 0.36 & 1 & 0.41 & 0.43 & 0.47 & 0.48 & 0.37 & 0.47 & 0.51 & 0.50 \\
Oki18a & 0.47 & 0.50 & 0.43 & 0.47 & 1 & 0.60 & 0.65 & 0.70 & 0.60 & 0.60 & 0.75 & 0.70 \\
Oki18b & 0.49 & 0.57 & 0.50 & 0.47 & 0.78 & 1 & 0.70 & 0.71 & 0.58 & 0.64 & 0.80 & 0.74 \\
Quir19a & 0.46 & 0.56 & 0.51 & 0.47 & 0.71 & 0.78 & 1 & 0.81 & 0.58 & 0.63 & 0.81 & 0.78 \\
Quir19b & 0.47 & 0.53 & 0.40 & 0.47 & 0.71 & 0.70 & 0.79 & 1 & 0.63 & 0.67 & 0.85 & 0.77 \\
\hline Jash19a & 0.43 & 0.51 & 0.50 & 0.49 & 0.60 & 0.59 & 0.62 & 0.59 & 1 & 0.58 & 0.67 & 0.62 \\
\hline Jash19b & 0.39 & 0.49 & 0.48 & 0.48 & 0.68 & 0.65 & 0.66 & 0.59 & 0.64 & 1 & 0.75 & 0.68 \\
Oki19a & 0.52 & 0.59 & 0.54 & 0.52 & 0.81 & 0.80 & 0.82 & 0.80 & 0.69 & 0.74 & 1 & 0.85 \\
\hline Oki19b & 0.53 & 0.60 & 0.54 & 0.49 & 0.83 & 0.83 & 0.79 & 0.77 & 0.63 & 0.68 & 0.90 \\
\hline
\end{tabular}

All correlations were significant at $P<0.0001$. "Quir" stands for Quirusillas, "Jash" for Jashore, and "Oki" for Okinawa, "18" and "19" for the 2017-18 or 2018 cycle and 2018-19 or 2019 cycle, respectively, and "a" and "b" for the first and second sowing, respectively. Cell shades change from green to red with the increase of correlation coefficients.

Incidence and Severity, with the former being the percentage of infected spikes and the latter the averaged percentage of infected spikelets. Additionally, days to heading $(\mathrm{DH})$ and plant height $(\mathrm{PH})$ were evaluated in all the experiments to investigate their potential association with WB resistance.

\section{Statistical analysis}

The PROC GLM module of SAS ver. 9.2 was used to perform analysis of variance (ANOVA), and the PROC CORR module was employed to calculate Pearson correlation coefficients. Broad sense heritability estimates were calculated with the formula $H^{2}=\sigma_{g}^{2} /\left(\sigma_{g}^{2}+\sigma_{g * y}^{2} / y+\sigma_{g * s}^{2} / s+\sigma_{e}^{2} / s y\right)$, where $\sigma_{g}^{2}$ is for genetic variance, $\sigma_{g * y}^{2}$ for genotype-by-year interaction, $\sigma_{g * s}^{2}$ for genotype-by-sowing interaction, $\sigma_{e}^{2}$ for error variance, $y$ for the number of years, and $s$ for the number of sowings.

\section{Genotyping}

Genomic DNA was isolated from young leaves with the CTAB method and then was subjected to the DArTseq genotyping platform at the Genetic Analysis Service for Agriculture (SAGA) at CIMMYT, Mexico. Additionally, four STS markers in the 2NS/2AS region were assayed in this study, including Ventriup-LN2 (Helguera et al. 2003), WGGB156 and WGGB159 (Wang et al. 2018), and cs/Vrgal3 that was developed from a follow-up study of Seah et al. (2001) (E. Lagudah, pers. comm.). Marker screening was conducted with the thresholds of $20 \%$ missing data points and $30 \%$ of minor allele frequency. Redundant markers were excluded from further analysis with the BIN module of the ICIMapping v. 4.1 software (www. isbreeding.net).

\section{Linkage and QTL mapping}

Linkage analysis was carried out with the JoinMap v.4 software (Van Ooijen 2006), using LOD scores from 5 to 10 for grouping individual linkage groups (LG) and the Maximum Likelihood algorithm for ordering markers in each LG. Assignment of LGs to chromosomes was done via BLAST searches of the DArTseq marker sequences against the Chinese Spring genome (CS IWGSC RefSeq v1.0). QTL analysis followed a two-step procedure using MapQTL v6.0 (Van Ooijen 2009), in which interval mapping (IM) was first used to detect potential QTL and their tightly linked markers. Then multiple QTL mapping was carried out for each QTL, using its most closely linked marker identified in IM as a cofactor. Significant QTL were reported when they have a LOD score of $>3.0$ in at least one experiment or $>2.0$ in multiple experiments. MapChart ver. 2.3 (Voorrips 2002) was used to draw LGs and LOD profiles.

\section{RESULTS \\ Phenotyping}

Disease pressure varied greatly across the 12 experiments. Jash18a exhibited the lowest grand means of WB index for the two populations, i.e., $25.1 \%$ for $\mathrm{AM}$ and $15.5 \%$ for $\mathrm{CM}$, and Oki19a showed the highest infection with $51.6 \%$ for AM and $44.3 \%$ for CM (Fig. 1). In $\mathrm{AM}$, the resistant parent Milan significantly outperformed the susceptible parent Alondra in most experiments, whereas both parents appeared to be similarly resistant in $\mathrm{CM}$, due to the use of Milan-R instead of Milan-S. Another observation is that Milan performed better in Quirusillas and Okinawa than in Jashore, possibly due to genotype-by-environment interaction (Fig. 1). ANOVA results indicated significant effects of "Genotype" and "Genotype $\times$ Year" in both populations across all locations, and moderately high heritability estimates ranging from 0.71 to 0.88 for AM and from 0.73 to 0.86 for CM were obtained (Table 1). Significant correlations of WB index were found among all experiments, with $r$-values ranging from 0.30 to 0.90 for $\mathrm{AM}$ and 0.32 to 0.85 for CM. Generally, experiments in Bolivia exhibited a better correlation than those in Bangladesh (Table 2). Correlation of WB with $\mathrm{DH}$ and $\mathrm{PH}$ was mostly nonsignificant, and the few significant correlations were of low levels (Table S1). Between WB and $\mathrm{PH}$, the significant correlations were all negative, except for Jash19b, in agreement with the general trend that tall plants have lower WB. Between WB and DH, all significant correlations in Jashore were positive, whereas those in Quirusillas and Okinawa were negative (Table S1).

\section{Genotyping and linkage analysis}

After marker screening, 1452 and 1445 high-quality nonredundant markers were respectively obtained for AM and CM for linkage analysis, generating 39 LGs for the former and 40 LGs for the latter population. These LGs represent all 21 wheat chromosomes, of which $2 \mathrm{~B}$ had the highest number of markers (169) and 4D had the lowest number of markers (18) for AM, and the corresponding chromosomes for CM are 5B (152) and 4D (7). These LGs covered a total genetic distance of $4979 \mathrm{cM}$ with an average distance between markers of $3.4 \mathrm{cM}$ for $\mathrm{AM}$, and $3370 \mathrm{cM}$ with $2.3 \mathrm{cM}$ for CM (Tables S2, S3). 


\section{QTL mapping}

In the AM population, four QTL were detected on chromosomes $2 \mathrm{AS}, 2 \mathrm{DL}, 7 \mathrm{AL}$, and 7DS, of which only the first one on 2NS/2AS was consistently significant across experiments, explaining phenotypic variation (PV) from 26.0 to $79.4 \%$, whereas other QTL were of minor effects and were less consistent across experiments (Table 3 and Fig. 2). The $2 \mathrm{DL}$ QTL was significant in six out of 12 experiments, being the second most repeatable QTL and explaining PV from 4.9 to $9.0 \%$. The 7AL and 7DS QTL were both significant in only two experiments. Milan contributed the resistant allele of the QTL on 2NS/2AS, whereas the susceptible parent Alondra contributed those of the remaining three QTL (Table 3).

In the CM population, seven QTL were identified on chromosomes 2AS, 2BS, 4AL, 5AS, 5DL, 7AS, and 7AL. Again the QTL on $2 \mathrm{NS} / 2 \mathrm{AS}$ was the only stably expressed QTL in all experiments, accounting for PV from 16.7 to $68.9 \%$, and the rest QTL were all of minor effects with PV less than 10\% (Table 3 and Fig. 3). The 5DL QTL was significant in 10 out of the 12 experiments, explaining PV from 3.4 to $6.0 \%$, and the rest of QTL were significant in only two to five experiments. The resistant parent Caninde\#2 contributed most resistance alleles, and Milan-S contributed only one for the 2BS QTL (Table 3).

Obviously, the 2AS QTL in both populations is associated with the $2 \mathrm{NS} / 2 \mathrm{AS}$ translocation region, which is on the distal region of 2AS that corresponds to a physical range of $4.0-21.2 \mathrm{Mb}$ in the CS genome, delimited by DArTSeq markers 3026108 and 1380019 (Tables 3, S4, Figs. 2, 3). The four STS markers Ventriup-LN2, cs/Vrgal3, WGGB156, and WGGB159 were found in this region, with the first two mostly distal to and the last two mostly proximal to the WB QTL (Figs. 2, 3). Additionally, QTL on 7AL in the two populations might be the same, based on a comparison of the genetic (Fig. S1) and physical positions (675.4-685.1 Mb) of the flanking markers.

QTL mapping for DH (Table S5) and PH (Table S6) were also conducted to identify potential loci associated with WB resistance. There was no such locus identified in the AM population, and only one DH QTL on 4AL identified in the CM population showed linkage with WB QTL (Tables 3, S5), in agreement with the low correlation between WB resistance and DH/PH (Table S1).

\section{DISCUSSION}

Due to the fast-spreading of WB into new continents and its devastating nature, researchers and breeders in many WB affected and threatened countries enhanced or initiated genetic studies on WB resistance in the hope to identify major QTL and their linked molecular markers that could be used in MAS. As far as we know, seven of such studies have been published, of which six reported the 2NS/2AS translocation as the only stably expressed QTL with major effects (Cruppe et al. 2020b; Ferreira et al. 2020; He et al. 2021; He et al. 2020b; Juliana et al. 2020; Wu et al. 2021). The remaining one by Goddard et al. (2020) targeted a non-2NS source BR 18-Terena with moderate WB resistance and identified several non-2NS resistance loci at seedling and head stages via in vitro experiments. Although a few QTL appeared to have PVs higher than $10 \%$, a conventional threshold for major QTL, their effects need to be confirmed in field experiments before being used in breeding. In the current study, the 2NS/2AS region appeared to be the only consistent QTL in both the $A M$ and CM populations, whereas none of the rest QTL was consistently identified across experiments, again demonstrating the narrow genetic base for WB resistance.

It is widely acknowledged that alien chromosome segments do not recombine with their homoeologous wheat chromosome regions, which is especially true for those alien fragments introduced via ph $1 b$ mutant or irradiation technologies (Qi et al. 2007). However, due to the close evolutional relationship between wheat and Aegilops species, spontaneous translocation often happens between genomes of the two species (Doussinault et al. 1983). Furthermore, 
Chr_2AS

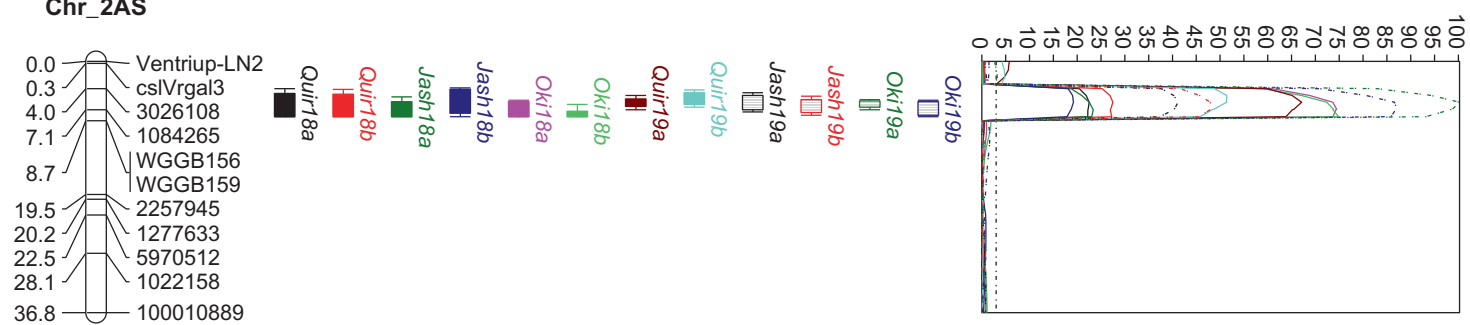

Chr_2DL

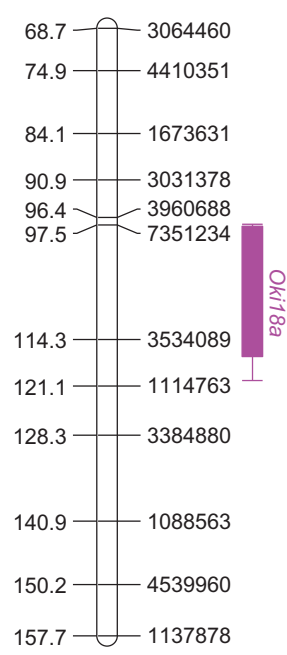

Chr_7DS

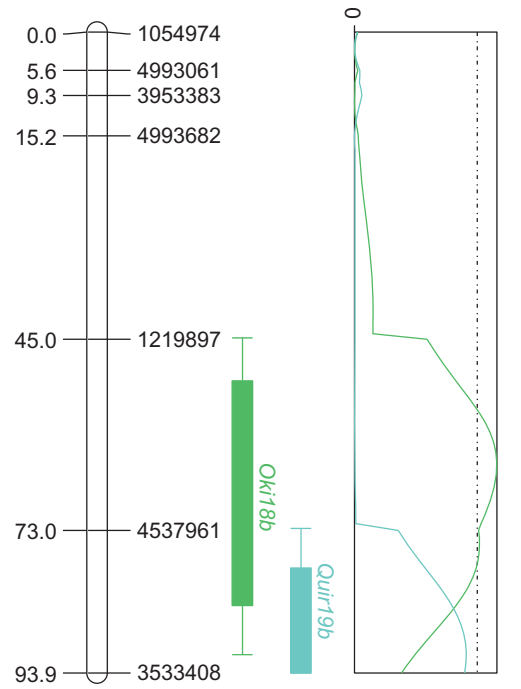

Chr_7AL

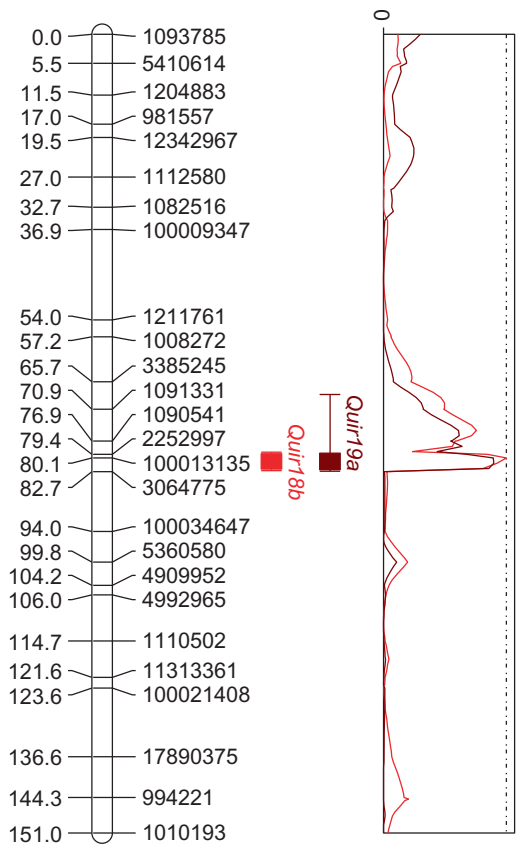

$$
\begin{array}{|l|}
\hline \rightarrow \text { Quir18a } \\
- \text { - Quir18b } \\
-- \text { Jash18a } \\
-- \text { Jash18b } \\
- \text { Oki18a } \\
- \text { Oki18b } \\
- \text { - Quir19a } \\
- \text { - Quir19b } \\
-- \text { Jash19a } \\
-- \text { Jash19b } \\
- \text { - Oki19a } \\
-- \text { Oki19b }
\end{array}
$$

Fig. 2 QTL profiles for wheat blast resistance in the Alondra/Milan population across experiments. Genetic distances are shown in centimorgans to the left side of the linkage groups. Only framework markers are presented except for the QTL region where all markers are shown. A threshold of 3.0 is indicated by a dashed vertical line in the LOD graph.

the introduced Aegilops chromosome segments are able to recombine at lower frequency with their counterparts in the wheat genome, which has been observed in the 2NS/2AS translocation region by many researchers (Bariana and McIntosh 1993; Bonhomme et al. 1995; Jahier et al. 2001; Robert et al. 2000). Recent QTL mapping studies where the 2NS/2AS translocation was involved also demonstrated the recombination within this region (Ferreira et al. 2020; He et al. 2020b; Xue et al. 2018). This enables the precision mapping (if not fine mapping) of the WB resistance QTL on the 2NS region.
Similar to our previous results in the Caninde\#1/Alondra population (He et al. 2020b), the WB QTL in the 2NS region was mapped proximal to STS markers Ventriup-LN2 and cs/Vrgal3 and distal to WGGB156 and WGGB159, except for three experiments for the CM population where the QTL was mapped distal to VentriupLN2 and cs/Vrgal3 (Fig. 3). By scrutinizing the LOD profiles, the peak region of this QTL appears more close to the STS marker WGGB156 with a physical position in CS at $16.6 \mathrm{Mb}$. This is in agreement with the published results, where markers with the highest LOD (for bi-parental populations) or the lowest $p$ value (for 

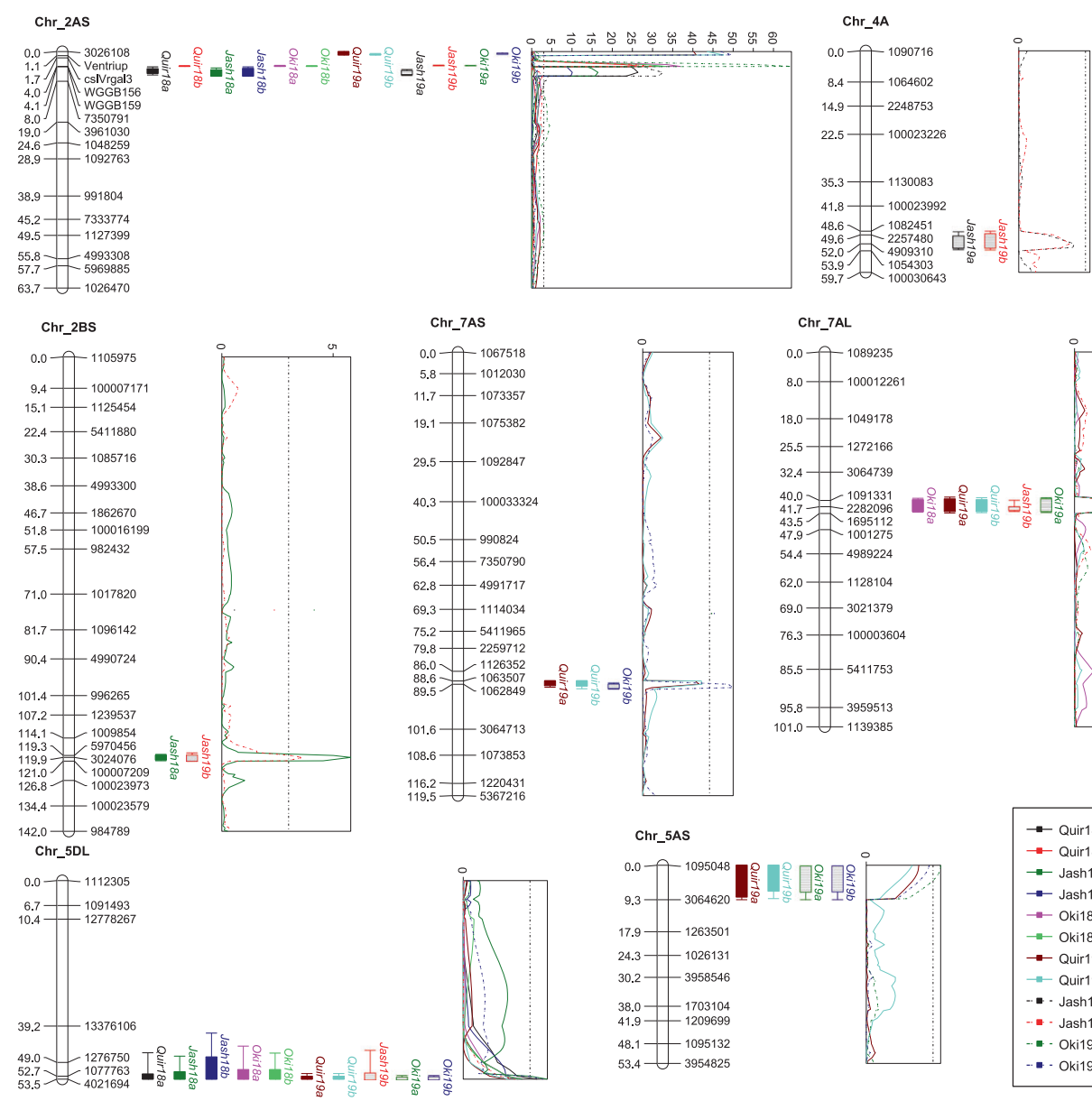

\section{.}


contrast to Fusarium head blight, another major spike disease of wheat (Xu et al. 2020). The main reason could be the low variation in $\mathrm{DH}$ and $\mathrm{PH}$ among lines of these populations, which significantly reduced the difference in micro-environment among spikes of different lines. Another possibility could be a lack of tight linkage between QTL for $\mathrm{DH} / \mathrm{PH}$ and those for WB resistance, leading to lower confounding effects of the two phenological traits on WB.

As an economical and easily adoptable management method, varietal resistance has been widely utilized in WB epidemic regions; however, most released cultivars with WB resistance are 2NS-based (Singh et al. 2021), making the resistance vulnerable to the fast evolving MoT isolates. Indeed, the 2NS-virulent strains have been identified in South America with increased frequency over time (Ceresini et al. 2018), making it imperative to search and utilize alternative WB resistance genes/QTL. Once the new resistant sources are identified, they will be utilized together or in rotation with the 2NS-based sources to reduce the high directional selection pressure that 2NS genotypes are imposing on the MoT population.

\section{CONCLUSION}

The QTL on the 2NS/2AS translocation was the only major QTL identified in the two mapping populations, which is not cosegregating with the commonly utilized diagnostic marker Ventriup-LN2, warranting the utilization of additional markers in this regain to better diagnose the presence of $2 \mathrm{NS}$. The multiple minor QTL could be potentially useful for WB resistance breeding if confirmed in other studies, in that case MAS is preferred considering their low phenotypic effects. Further efforts are imperative to identify non-2NS resistance with strong phenotypic effects for WB resistance breeding to slow down the evolution of MoT-virulent isolates.

\section{DATA AVAILABILITY}

The raw genotypic and phenotypic data of this article are available at https://hdl. handle.net/11529/10548581.

\section{REFERENCES}

Bariana HS, McIntosh RA (1993) Cytogentic studies in wheat. XV. Location of rust resistance genes in VPM1 and their genetic linkage with other disease resistance genes in chromosome 2A. Genome 36(3):476-482

Bonhomme A, Gale MD, Koebner RMD, Nicolas P, Jahier J, Bernard M (1995) RFLP analysis of an Aegilops ventricosa chromosome that carries a gene conferring resistance to leaf rust (Puccinia recondita) when transferred to hexaploid wheat. Theor Appl Genet 90(7-8):1042-1048

Cao X, Chen L, Zhou Y, Duan X (2011) Potential distribution of Magnaporthe grisea in China and the world, predicted by MaxEnt. Plant Prot 37(03):80-83

Castroagudín VL, Ceresini PC, De Oliveira SC, Reges JTA, Maciel JLN, Bonato ALV et al. (2015) Resistance to Qol fungicides is widespread in Brazilian populations of the wheat blast pathogen Magnaporthe oryzae. Phytopathology 105(3):284-294

Ceresini PC, Castroagudín VL, Rodrigues FÁ, Rios JA, Aucique-Pérez CE, Moreira SI et al. (2018) Wheat blast: Past, present, and future. Annu Rev Phytopathol 56 (1):427-456

Cruppe G, Cruz CD, Peterson G, Pedley K, Asif M, Fritz A et al. (2020a) Novel sources of wheat head blast resistance in modern breeding lines and wheat wild relatives. Plant Dis 104(1):35-43

Cruppe G, Silva P, Lemes da Silva C, Peterson G, Pedley KF, Cruz CD et al. (2020b) Genomewide association reveals limited benefits of pyramiding the $1 \mathrm{~B}$ and $1 \mathrm{D}$ loci with the $2 N^{\vee} S$ translocation for wheat blast control. Crop Sci 61(2):1089-1103

Cruz CD, Magarey RD, Christie DN, Fowler GA, Fernandes JM, Bockus WW et al. (2016a) Climate suitability for Magnaporthe oryzae Triticum pathotype in the United States. Plant Dis 100(10):1979-1987

Cruz CD, Peterson GL, Bockus WW, Kankanala P, Dubcovsky J, Jordan KW et al. (2016b) The 2NS translocation from Aegilops ventricosa confers resistance to the Triticum pathotype of Magnaporthe oryzae. Crop Sci 56:990-1000

Cruz CD, Valent B (2017) Wheat blast disease: danger on the move. Tropical Plant Pathol 42(3):210-222
Doussinault G, Delibes A, Sanchez-Monge R, Garcia-Olmedo F (1983) Transfer of a dominant gene for resistance to eyespot disease from a wild grass to hexaploid wheat. Nature 303(5919):698-700

Duveiller E, He X, Singh PK (2016) Wheat blast: an emerging disease in South America potentially threatening wheat production. In: Bonjean A, van Ginkel M (eds) The World Wheat Book Vol 3. Lavoisier, Paris, pp 1107-1122

Duveiller E, Hodson D, Sonder K, Tiedermann AV (2011) An international perspective on wheat blast. Phytopathology 101:S220

Ferreira JR, Torres GAM, Consoli L, Camilotti GA, Scagliusi SMM, Nhani A et al. (2020) Quantitative trait loci conferring blast resistance in hexaploid wheat at adult plant stage. Plant Pathol 70(1):100-109

Gao L, Kielsmeier-Cook J, Bajgain P, Zhang X, Chao S, Rouse MN et al. (2015) Development of genotyping by sequencing (GBS)- and array-derived SNP markers for stem rust resistance gene Sr42. Mol Breed 35(11):207

Gao L, Koo DH, Juliana P, Rife T, Singh D, Lemes da Silva C et al. (2021) The Aegilops ventricosa $2 \mathrm{~N}(\mathrm{v}) \mathrm{S}$ segment in bread wheat: cytology, genomics and breeding. Theor Appl Genet 134(2):529-542

Goddard R, Steed A, Chinoy C, Ferreira JR, Scheeren PL, Maciel JLN et al. (2020) Dissecting the genetic basis of wheat blast resistance in the Brazilian wheat cultivar BR 18-Terena. BMC Plant Biol 20(1):398

He X, Gupta V, Bainsla NK, Chawade A, Singh PK (2020a) Breeding for wheat blast resistance. In: Kumar S, Kashyap PL, Singh GP (eds) Wheat Blast. CRC Press, Boca Raton, pp 163-174

He X, Juliana P, Kabir MR, Roy KK, Islam R, Marza F et al. (2021) Screening and mapping for head blast resistance in a panel of CIMMYT and South Asian bread wheat germplasm. Front Genet 12:679162

He X, Kabir MR, Roy KK, Anwar MB, Xu K, Marza F et al. (2020b) QTL mapping for field resistance to wheat blast in the Caninde\#1/Alondra population. Theor Appl Genet 133(9):2673-2683

Helguera M, Khan IA, Kolmer J, Lijavetzky D, Zhong-qi L, Dubcovsky J (2003) PCR assays for the Lr37-Yr17-Sr38 cluster of rust resistance genes and their use to develop isogenic hard red spring wheat lines. Crop Sci 43(5):1839-1847

Jahier Abelard, Tanguy Dedryver, Rivoal Khatkar et al. (2001) The Aegilops ventricosa segment on chromosome 2AS of the wheat cultivar 'VPM1' carries the cereal cyst nematode resistance gene Cre5. Plant Breed 120(2):125-128

Juliana P, He X, Kabir MR, Roy KK, Anwar MB, Marza F et al. (2020) Genome-wide association mapping for wheat blast resistance in CIMMYT's international screening nurseries evaluated in Bolivia and Bangladesh. Sci Rep. 10(1):15972

Juliana P, Poland J, Huerta-Espino J, Shrestha S, Crossa J, Crespo-Herrera L et al. (2019) Improving grain yield, stress resilience and quality of bread wheat using largescale genomics. Nat Genet 51(10):1530-1539

Kohli MM, Mehta YR, Guzman E, De Viedma L, Cubilla LE (2011) Pyricularia blast - a threat to wheat cultivation. Czech J Genet Plant 47:S130-S134

Maciel JLN (2011) Magnaporthe oryzae, the blast pathogen: current status and options for its control. In: Hemming D (ed) Plant Sciences Reviews. CABI, UK, pp 233-240

Malaker PK, Barma NC, Tewari TP, Collis WJ, Duveiller E, Singh PK et al. (2016) First report of wheat blast caused by Magnaporthe oryzae pathotype Triticum in Bangladesh. Plant Dis 100:2330

Mottaleb KA, Singh PK, Sonder K, Kruseman G, Tiwari TP, Barma NCD et al. (2018) Threat of wheat blast to South Asia's food security: an ex-ante analysis. PLoS ONE 13(5):e0197555

Qi L, Friebe B, Zhang P, Gill BS (2007) Homoeologous recombination, chromosome engineering and crop improvement. Chromosome Res 15(1):3-19

Robert O, Dedryver F, Leconte M, Rolland B, De Vallavieille-Pope C (2000) Combination of resistance tests and molecular tests to postulate the yellow rust resistance gene Yr17 in bread wheat lines. Plant Breed 119(6):467-472

Seah S, Bariana H, Jahier J, Sivasithamparam K, Lagudah ES (2001) The introgressed segment carrying rust resistance genes $\mathrm{Yr} 17, \mathrm{Lr} 37$ and $\mathrm{Sr} 38$ in wheat can be assayed by a cloned disease resistance gene-like sequence. Theor Appl Genet 102(4):600-605

Singh PK, Gahtyari NC, Roy C, Roy KK, He X, Tembo B et al. (2021) Wheat blast: a disease spreading by intercontinental jumps and its management strategies. Front Plant Sci 12:710707

Tembo B, Mulenga RM, Sichilima S, M'Siska KK, Mwale M, Chikoti PC et al. (2020) Detection and characterization of fungus (Magnaporthe oryzae pathotype Triticum) causing wheat blast disease on rain-fed grown wheat (Triticum aestivum L.) in Zambia. Plos ONE 15(9):e0238724

Urashima AS, Grosso CRF, Stabili A, Freitas EG, Silva CP, Netto DCS et al. (2009) Effect of Magnaporthe grisea on seed germination, yield and quality of wheat. Advances in Genetics, Genomics and Control of Rice Blast Disease. Springer: New York, pp 267-277

Van Ooijen J (2006) JoinMap 4 , Software for the calculation of genetic linkage maps in experimental populations. Kyazma BV: Wageningen, Netherlands 
Van Ooijen J (2009) MapQTL ${ }^{\circ}$, Software for the mapping of quantitative trait loci in experimental populations of diploid species. Kyazma BV: Wageningen, Netherlands

Voorrips RE (2002) MapChart: software for the graphical presentation of linkage maps and QTLs. J Hered 93(1):77-78

Wang Y, Zhang H, Xie J, Guo B, Chen Y, Zhang H et al. (2018) Mapping stripe rust resistance genes by BSR-Seq: YrMM58 and YrHY1 on chromosome 2AS in Chinese wheat lines Mengmai 58 and Huaiyang 1 are Yr17. Crop J 6(1):91-98

Wu L, He X, Rezaul Kabir M, Roy KK, Babul Anwar M, Marza F et al. (2021) Genetic sources and loci for wheat head blast resistance identified by genome-wide association analysis. Crop J. Online first. https://doi.org/10.1016/j.cj.2021.07.007

Xu K, He X, Dreisigacker S, He Z, Singh PK (2020) Anther extrusion and its association with Fusarium head blight in CIMMYT wheat germplasm. Agronomy 10(1):47

Xue S, Kolmer JA, Wang S, Yan L (2018) Mapping of leaf rust resistance genes and molecular characterization of the 2NS/2AS translocation in the wheat cultivar Jagger. G3: Genes, Genomes, Genet 8(6):2059-2065

\section{ACKNOWLEDGEMENTS}

Financial supports from the CGIAR Research Program on WHEAT, Indian Council of Agricultural Research, India, Vetenskapsrådet (the Swedish Research Council), Sweden, and Australian Center for International Agricultural Research, Australia, are gratefully acknowledged. Technical support from Jose Asister, Jhonny Villagomez, Roberto Butron, and Francisco Lopez in field trials in Bolivia, Tanusree Roy, and Rokshana Begum in field trials in Bangladesh, Mayela Flores in genotyping work (STS markers) at CIMMYT-Mexico is highly acknowledged.

\section{AUTHOR CONTRIBUTIONS}

PKS conceived and designed the experiments; MRK, KKR, FM, XH, CSP, and PKS contributed to field trials; $\mathrm{XH}$ and $\mathrm{AC}$ conducted genotyping activities; $\mathrm{ED}$ and PKS developed plant materials; $\mathrm{XH}$ analyzed the data and wrote the first draft of the paper, and all co-authors contributed and approved the final draft of the paper.

\section{COMPETING INTERESTS}

The authors declare no competing interests.

\section{ADDITIONAL INFORMATION}

Supplementary information The online version contains supplementary material available at https://doi.org/10.1038/s41437-021-00480-3.

Correspondence and requests for materials should be addressed to Pawan K. Singh.

Reprints and permission information is available at http://www.nature.com/ reprints

Publisher's note Springer Nature remains neutral with regard to jurisdictional claims in published maps and institutional affiliations.
Open Access This article is licensed under a Creative Commons Attribution 4.0 International License, which permits use, sharing, adaptation, distribution and reproduction in any medium or format, as long as you give appropriate credit to the original author(s) and the source, provide a link to the Creative Commons license, and indicate if changes were made. The images or other third party material in this article are included in the article's Creative Commons license, unless indicated otherwise in a credit line to the material. If material is not included in the article's Creative Commons license and your intended use is not permitted by statutory regulation or exceeds the permitted use, you will need to obtain permission directly from the copyright holder. To view a copy of this license, visit http://creativecommons. org/licenses/by/4.0/.

(c) The Author(s) 2021 